\title{
Temsirolimus in Asian Metastatic/Recurrent Non-clear Cell Renal Carcinoma
}

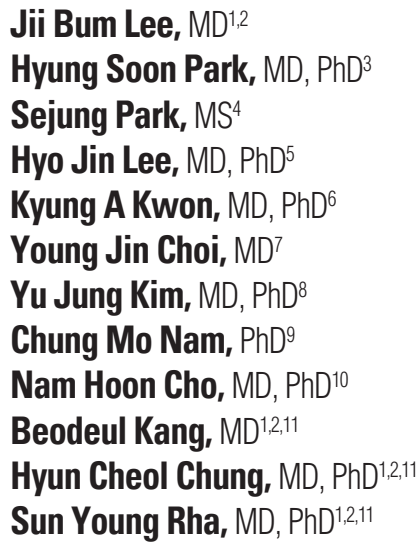

*A list of author's affiliations appears at the end of the paper.

Correspondence: Sun Young Rha, MD, PhD Division of Medical Oncology, Department of Internal Medicine, Yonsei University College of Medicine, 50-1 Yonsei-ro, Seodaemun-gu, Seoul 03722, Korea

Tel: 82-2-2228-8053

Fax: 82-2-362-5592

E-mail: rha7655@yuhs.ac

Received December 3, 2018

Accepted April 8, 2019

Published Online April 16, 2019

\begin{abstract}
Purpose
Temsirolimus is effective in the treatment for metastatic non-clear cell renal cell carcinoma (nccRCC) with poor prognosis. We aim to investigate the efficacy and tolerability of temsirolimus in treatment of naïve Asian patients with metastatic/recurrent nccRCC.
\end{abstract}

\section{Materials and Methods}

From January 2008 to July 2017, data of treatment-naïve, metastatic/recurrent nccRCC patients, who were treated with temsirolimus according to the standard protocol, were collected. The primary end-point was progression-free survival (PFS). Secondary end points were overall survival (OS), objective response rate (ORR), and tolerability of temsirolimus.

\section{Results}

Forty-four metastatic/recurrent nccRCC patients, 10 from prospective and 34 from retrospective groups, were enrolled; 24 patients (54\%) were papillary type, and other histology subtypes included 11 chromophobes (25\%), two collecting ducts (5\%), one Xp11.2 translocation (2\%), and six others (14\%). The median PFS and OS were 7.6 months and 17.6 months, respectively. ORR was $11 \%$ and disease control rate was $83 \%$. Patients with prior nephrectomy had longer PFS (hazard ratio [HR], 0.16; 95\% confidence interval [Cl], 0.06 to $0.42 ; \mathrm{p}<0.001$ ) and OS (HR, $0.15 ; 95 \% \mathrm{Cl}, 0.05$ to $0.45 ; \mathrm{p}<0.001$ ). Compared to favorable/intermediate prognosis group, poor prognosis group had shorter median PFS (4.7 months vs. 7.6 months [HR, 2.91; 95\% $\mathrm{Cl}, 1.39$ to 6.12; $\mathrm{p}=0.005])$ and median OS (9.2 months vs. 17.6 months [HR, 2.84; $95 \% \mathrm{Cl}, 1.23$ to $6.56 ; \mathrm{p}=0.015]$ ).

\section{Conclusion}

Temsirolimus not only benefits poor-risk nccRCC patients, but it is also effective in favorable or intermediate-risk group in Asians. Temsirolimus was well-tolerated with manageable adverse events.

\section{Introduction}

Renal cell cancer (RCC) is a heterogeneous disease that is diversified by its pathologic subtypes, genetic alterations, and clinical outcomes [1,2]. It is mainly divided into two pathological subtypes based on pathologic phenotype, clear cell, and non-clear cell types, with the latter defined as less than $50 \%$ of clear cells [3].

The incidence of non-clear cell RCC (nccRCC) is no more
Key words

Temsirolimus, First-line, Asian, Renal cell carcinoma, Efficacy, Tolerability than $8 \%-20 \%$ [4]. Its rarity and poor prognosis have made it difficult to determine the best treatment option. In recent years, tyrosine kinase inhibitors (TKIs) targeting vascular endothelial growth factor receptor (VEGFR) pathways, such as sunitinib $[5,6]$ and sorafenib $[7,8]$, and mammalian target of rapamycin (mTOR) inhibitors, such as temsirolimus $[9,10]$ and everolimus [11,12], have been developed for the treatment of advanced/metastatic RCC [13]. Temsirolimus is an inhibitor of mTOR kinase, which is part of a signaling pathway associated with growth and proliferation of cells. Dis- 
ruption of mTOR thereby results in suppression of cell cycle and angiogenesis $[14,15]$.

Global Advanced Renal Cell Cancer (ARCC) phase 3 trial showed that 40 nccRCC treatment-naïve patients with poor prognosis, who received temsirolimus, had a median progression-free survival (mPFS) of 3.8 months and median overall survival (mOS) of 10.9 months. However, there is no data on the efficacy of temsirolimus in less extensive, relatively favorable and intermediate prognosis in nccRCC, especially in Asian patients.

The aim of this retrospective, multicenter prospective study is to investigate the efficacy and tolerability of temsirolimus in treatment-naïve Asian patients with metastatic/recurrent nccRCC.

\section{Materials and Methods}

\section{Study design}

This is a combined analysis of 44 patients from the prospective study and retrospectively collected cases. Data of 10 patients from prospective group were collected from five medical centers that participated in a non-randomized, phase II, multicenter prospective trial from May 2011 to February 2015. The study was closed prematurely when temsirolimus was approved by Ministry of Food and Drug Safety and reimbursed in South Korea on June 1, 2011, as the standard first-line treatment for metastatic/recurrent nccRCC. Then, 34 patients who received temsirolimus using the same protocol of the prospective study at Yonsei Cancer Center from January 2008 to July 2017 were retrospectively analyzed in conjunction with the prospective group.

The primary end-point was progression-free survival (PFS). Secondary end points were overall survival (OS), objective response rate (ORR), disease control rate, safety, and tolerability of temsirolimus.

\section{Patient selection}

Inclusion criteria included histologically confirmed nccRCC (papillary, chromophobe, collecting duct, Xp11.2 translocation, others as unclassified) defined as metastatic and recurrent stage IV with a measurable or evaluable lesion by Response Evaluation Criteria in Solid Tumors (RECIST); Eastern Cooperative Oncology Group (ECOG) performance status 0-2; and adequate liver, renal, bone marrow functions. Before enrollment, pathology including questionable cases was reviewed by a pathologist who specialized in urology pathology at Yonsei Cancer Center. Patients were ineligible if they had received any prior chemotherapy treatment for renal cell carcinoma.

\section{Treatment and evaluation}

The patients received $25 \mathrm{mg}$ of temsirolimus administered in a weekly 30-minute intravenous infusion, and four weekly infusions were considered as one cycle. Treatment continued until unacceptable toxicity, disease progression, death, or patient's withdrawal of consent. Doses were interrupted based on relevant hematologic and non-hematologic effects, according to National Cancer Center Institute-Common Terminology Criteria of Adverse Events (NCI-CTCAE v.4.0). Dose was not reduced if adverse events (AEs) could be managed with conservative care. Temsirolimus was withheld for a maximum of 3 weeks for grade 3 or 4 AEs, and restarted at a reduced dose after recovery to grade 2 or lower. Dose was reduced to $20 \mathrm{mg} / \mathrm{m}^{2}$ weekly, and there was no reduction of more than $15 \mathrm{mg} / \mathrm{m}^{2}$ weekly.

To evaluate tumor size, computed tomography was repeated every two cycles (4 weeks considered as one cycle) with RECIST criteria 1.1. In patients who were enrolled in the prospective study, chest computed tomography evaluation was performed at the time of baseline and 8 weeks after treatment to evaluate pulmonary toxicity, such as noninfectious pneumonitis. Both Memorial Sloan Kettering Cancer Center (MSKCC) and ARCC risk groups, with the latter including the criteria of metastatic lesions in $\geq 2$ organs, were used to determine prognosis.

\section{Statistics}

Descriptive analysis was used to describe baseline characteristics and AEs. Survival curves were calculated using the Kaplan-Meier method. All statistical analyses were performed using SPSS statistical software ver. 25 (IBM Corp., Armonk, NY), SAS software ver. 9.4 (SAS Inc., Cary, NC), and R software ver. 3.5.0, (R Foundation for Statistical Computing, Vienna, Austria).

In prospective study, the following assumptions were made in the estimation of required sample size for primary end-point, PFS. The null hypothesis was that PFS $\left(\mathrm{H}_{0}\right)$ is 3.1 months. $\mathrm{H}_{0}$ was estimated from the previous trial of interferon $\alpha$ with PFS of 3.1 months. If temsirolimus had PFS of less than 3.1 months, trial would not proceed. The alternative hypothesis $\left(\mathrm{H}_{1}\right)$ was that PFS will be 5.5 months for treatment-naïve patients. This was based on the previous study of treatment-naïve and previously treated RCC patients who had similar PFS of 5.5 months and 6.3 months, respectively [13]. Sample size was calculated using Simon's optimal twostage design. With one-sided significance level of 0.05 , a power of 0.9 to reject the null hypothesis, and a 10\% drop- 
Table 1. Baseline characteristics

\begin{tabular}{|c|c|}
\hline Variable & No. $(\%)(n=44)$ \\
\hline Age, median (range) & $52(17-84)$ \\
\hline \multicolumn{2}{|l|}{ Sex } \\
\hline Male & $32(73)$ \\
\hline Female & $12(23)$ \\
\hline \multicolumn{2}{|l|}{ Histology } \\
\hline Papillary & $24(54)$ \\
\hline Chromophobe & $11(25)$ \\
\hline Collecting duct & $2(5)$ \\
\hline Xp11.2 translocation & $1(2)$ \\
\hline Others & $6(14)$ \\
\hline \multicolumn{2}{|l|}{ Sarcomatoid component } \\
\hline Yes & $13(29)$ \\
\hline No & $31(71)$ \\
\hline \multicolumn{2}{|l|}{ Initial stage of diagnosis } \\
\hline I & $5(11)$ \\
\hline II & $3(7)$ \\
\hline III & $6(14)$ \\
\hline IV & $30(68)$ \\
\hline \multicolumn{2}{|l|}{ Previous nephrectomy } \\
\hline Curative & $19(43)$ \\
\hline Cytoreductive & $11(25)$ \\
\hline \multicolumn{2}{|l|}{ Previous radiotherapy } \\
\hline Yes & $2(5)$ \\
\hline No & $42(95)$ \\
\hline \multicolumn{2}{|l|}{ No. of metastatic sites } \\
\hline 0 & $1(2)$ \\
\hline 1 & $26(59)$ \\
\hline 2 & $11(25)$ \\
\hline$\geq 3$ & $6(14)$ \\
\hline \multicolumn{2}{|l|}{ Sites of metastatic disease } \\
\hline Lung & $17(39)$ \\
\hline Lymph node & $18(41)$ \\
\hline Bone & $12(27)$ \\
\hline Liver & $9(21)$ \\
\hline \multicolumn{2}{|l|}{ ARCC parameter } \\
\hline Low hemoglobina) & $26(59)$ \\
\hline $\begin{array}{l}\text { Elevated calcium }>10 \mathrm{mg} / \mathrm{dL} \\
(>2.5 \mathrm{mmol} / \mathrm{L})\end{array}$ & $2(5)$ \\
\hline Elevated LDH & $7(16)$ \\
\hline Performance status $<80 \%$ & $3(7)$ \\
\hline $\begin{array}{l}\text { Time from diagnosis to } \\
\text { systemic treatment }<1 \mathrm{yr}\end{array}$ & $32(73)$ \\
\hline No. of metastatic sites $\geq 2$ & $17(39)$ \\
\hline \multicolumn{2}{|l|}{ ECOG } \\
\hline 0 & $33(75)$ \\
\hline 1 & $8(18)$ \\
\hline 2 & $3(7)$ \\
\hline
\end{tabular}

(Continued)
Table 1. Continued

$\begin{array}{lc}\text { Variable } & \text { No. }(\%)(\mathbf{n}=44) \\ \text { ARCC } & \\ \text { Favorable (0) } & 5(11) \\ \text { Intermediate (1-2) } & 24(55) \\ \text { Poor }(\geq 3) & 15(34) \\ \text { MSKCC } & \\ \quad \text { Favorable (0) } & 6(14) \\ \text { Intermediate (1-2) } & 34(77) \\ \quad \text { Poor ( } \geq 3) & 4(9) \\ \text { 2nd-line treatment } & 11(25) \\ \text { Yes } & 33(75) \\ \text { No }\end{array}$

ARCC, Advanced Renal Cell Cancer; LDH, lactate dehydrogenase; ECOG, Eastern Cooperative Oncology Group; MSKCC, Memorial Sloan Kettering Cancer Center. a)Men $<13.5 \mathrm{~g} / \mathrm{dL}$, women $<12.0 \mathrm{mg} / \mathrm{dL}$.

out rate, the final sample size was calculated to be 30 patients.

\section{Ethical statement}

This study was conducted in accordance with the Declaration of Helsinki, and was consistent with Good Clinical Practice. The institutional review board (IRB) of six centers approved the study protocol (IRB No. 4-2017-0727), and the study was registered in Korean Cancer Study Group (KCSG) (No: GU11-03). All patients from the retrospective cases were exempted from the written consent, according to the study protocol approved by IRB of Severance Hospital (IRB No. 4-2017-1056).

\section{Results}

\section{Patient characteristics}

In this study, a total of 44 patients were enrolled; 10 from prospective group and 34 from retrospective group. Table 1 lists the baseline characteristics of patients. The median age was 52 years (range, 17 to 84 years), and 32 patients (73\%) were male. Twenty-four patients (54\%) were papillary type renal cell carcinoma (pRCC), and among them, 19 patients were categorized as type $2 \mathrm{pRCC}$ (two patients had type 1 pRCC, three patients were not sub-classified). Other histology subtypes included 11 chromophobes (25\%), two collect- 
Table 2. Summary of response

\begin{tabular}{|lc} 
Best response & $\begin{array}{c}\text { No. of evaluable } \\
\text { patients }(\%)(\mathbf{n}=35)\end{array}$ \\
\hline CR & $3(9)$ \\
PR & $1(3)$ \\
\hline SD & $25(70)$ \\
PD & $6(18)$ \\
\hline Response rate $(C R+P R)$ & $4(11)$ \\
\hline Disease control rate (CR+PR+SD) & $29(83)$ \\
\hline Duration of treatment, median (range, wk) & $11(1-209)$ \\
\hline Patients with $\geq \mathbf{1}$ dose reduction-number & $13(30)$ \\
\hline Patients with $\geq \mathbf{1}$ dose delay-number & $15(34)$ \\
\hline
\end{tabular}

$\mathrm{CR}$, complete response; $\mathrm{PR}$, partial response; $\mathrm{SD}$, stable disease; $\mathrm{PD}$, progressive disease.

ing ducts (5\%), one Xp11.2 translocation (2\%), and six others $(14 \%)$. Thirteen patients $(71 \%)$ had sarcomatoid components.

Thirty patients were initially diagnosed as stage IV, and two-thirds of the patients had nephrectomy, 19 for curative and 11 for cytoreductive purposes. Except for one patient who had local relapse, 43 patients had one or more metastatic sites such as lung, lymph node, bone, and liver metastasis. Most of the patients $(80 \%)$ were treated within a year after initial diagnosis. When patients were categorized by risk groups, 15 patients were classified as poor-risk according to ARCC criteria and four patients by MSKCC criteria.

A

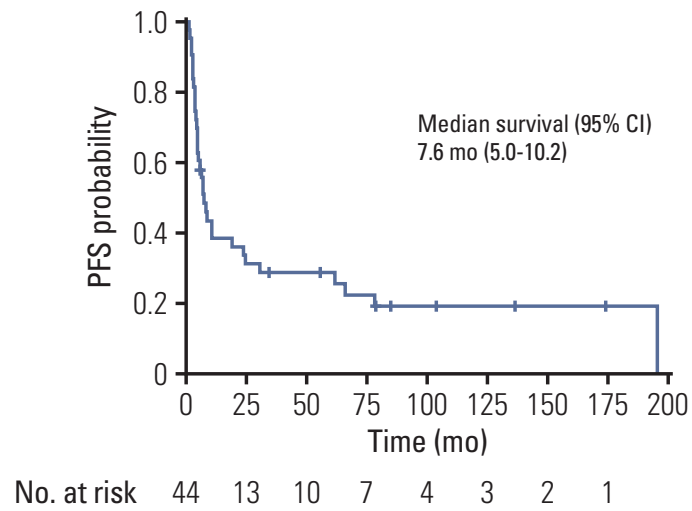

\section{Efficacy}

Out of 44 patients, 35 patients were evaluable. Three patients $(9 \%)$ showed complete response, one patient $(3 \%)$ showed partial response, and 25 patients (70\%) showed stable disease, resulting in overall response rate (ORR) of $11 \%$ and disease control rate (DCR) of $83 \%$ (Table 2). The duration of response was at least 15 months (median, 29.2 months; 95\% confidence interval [CI], 15.60 to 66.40 ) for all four respondents, and responses were maintained at the time of data analysis. At the time of analysis, 34 patients showed disease progression and 26 patients died. The cause of death was disease progression for 24 patients. The median PFS was 7.6 months (95\% CI, 5.0 to 10.2) and median OS was 17.6 months (95\% CI, 0 to 39.1) (Fig. 1).

The patients were further subdivided into pathological subtypes, sarcomatoid features, and prognosis groups. No significant difference in PFS or OS was observed in histological subtypes (Figs. 2 and 3). There was also no correlation between PFS and sarcomatoid features. However, patients without sarcomatoid features had longer OS (33.7 months) compared to patients with sarcomatoid features (9.2 months) $(p=0.025)$. Poor prognosis group defined by ARCC criteria had a trend for shorter PFS and OS. PFS of poor prognostic group was 4.7 months compared to 19.3 months of favorable/ intermediate group ( $\mathrm{p}=0.005)$. OS was 9.2 months $(95 \%$ CI, 1.23 to 6.56) in poor prognostic group and 43.1 months in favorable/intermediate group $(\mathrm{p}=0.015)$.

\section{Safety and tolerability}

Table 3 shows AEs. During treatment, 37 patients (84\%) experienced one or more AEs. Thirty patients $(68 \%)$ had

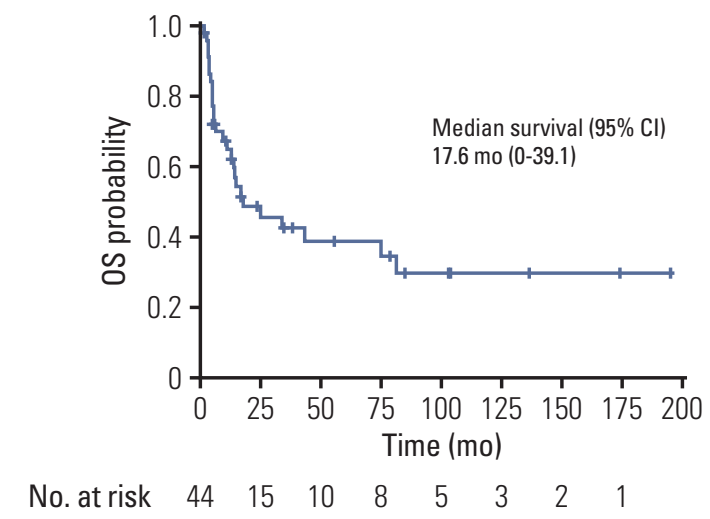

Fig. 1. Efficacy of temsirolimus in non-clear cell renal cell carcinoma. (A) Progression-free survival (PFS). (B) Overall survival (OS). CI, confidence interval. 
A

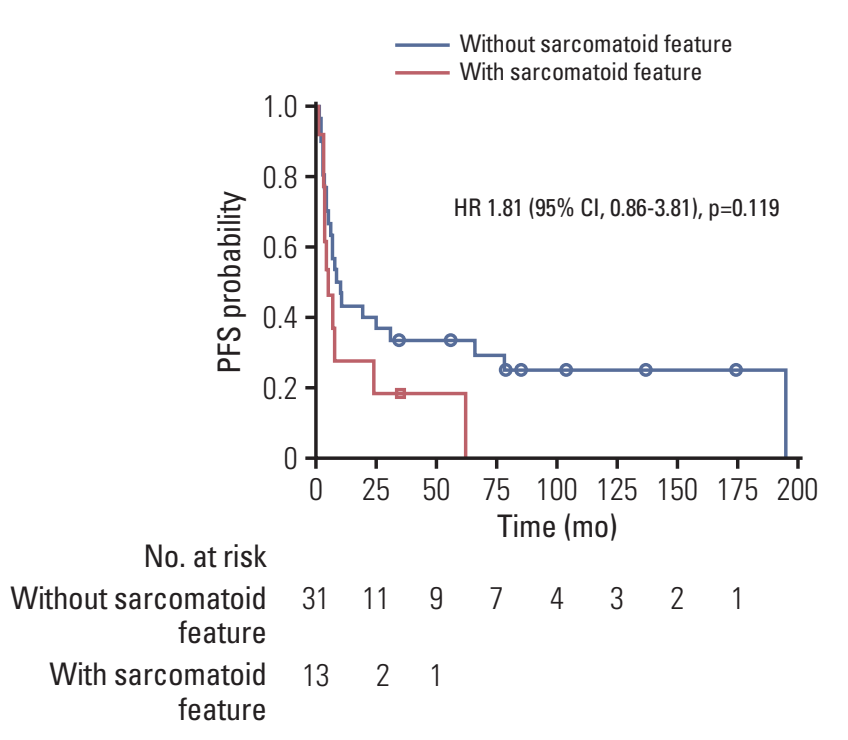

No. at risk

$\begin{array}{rcccccccc}\begin{array}{r}\text { Without sarcomatoid } \\ \text { feature }\end{array} & 31 & 11 & 9 & 7 & 4 & 3 & 2 & 1 \\ \begin{array}{r}\text { With sarcomatoid } \\ \text { feature }\end{array} & 13 & 2 & 1 & & & & & \end{array}$

C
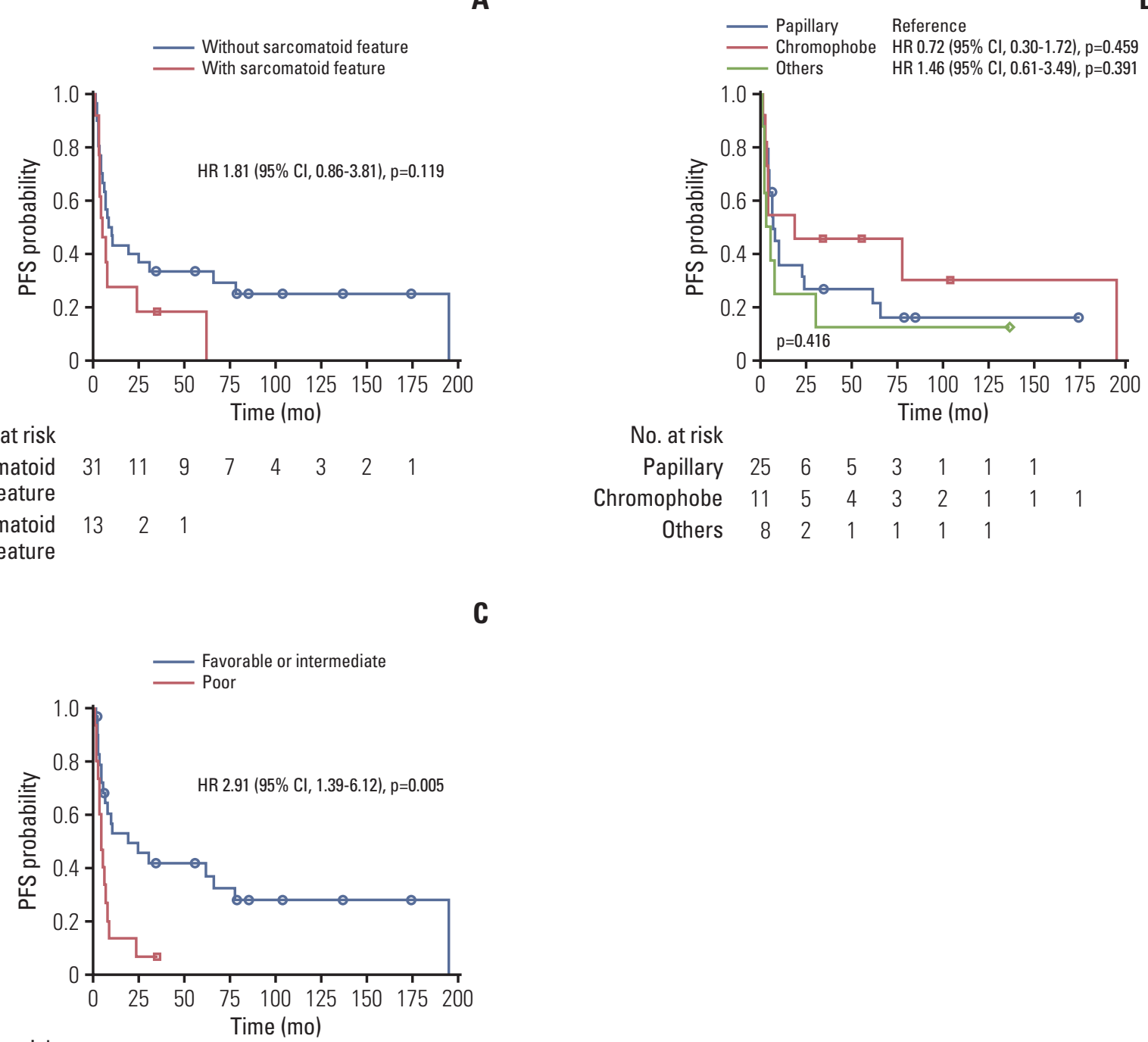

No. at risk

$\begin{array}{lllllllll}\text { Favorable or } & 29 & 12 & 10 & 7 & 4 & 3 & 2 & 1\end{array}$ intermediate

Poor $15 \quad 1$

Fig. 2. Kaplan-Meier curves of progression-free survival (PFS) according to subgroups. (A) With or without sarcomatoid features. (B) Papillary, chromophobe, others. (C) Prognostic group by Advanced Renal Cell Cancer criteria. HR, hazard ratio; $\mathrm{CI}$, confidence interval.

symptoms/signs, and 27 patients $(61 \%)$ had lab/imaging abnormalities that were related to temsirolimus. The most common AEs were stomatitis (34\%), fatigue (27\%), anorexia $(18 \%)$, and rash $(16 \%)$. The most frequent laboratory and imaging abnormalities were hyperglycemia $(23 \%)$, hypercholesterolemia $(18 \%)$, hypertriglyceridemia $(16 \%)$, and noninfectious pneumonitis (16\%). Particularly, AEs of grade $>3$ were noted in stomatitis $(9 \%)$, hypertriglyceridemia $(11 \%)$, hyperglycemia (9\%), and noninfectious pneumonitis (7\%). Twenty-six patients (59\%) who experienced AEs of grade 3 had dose reduction or delayed treatment. A total of four patients $(9 \%)$ discontinued treatment due to stomatitis (one patient), noninfectious pneumonitis (two patients), and creatinine elevation (one patient). There was no treatment-related mortality.

The median duration of treatment was 11 weeks (ranging from 1 to 209). Thirteen patients (30\%) had more than one dose reduction, and 15 patients $(34 \%)$ had more than one dose delays. 
A

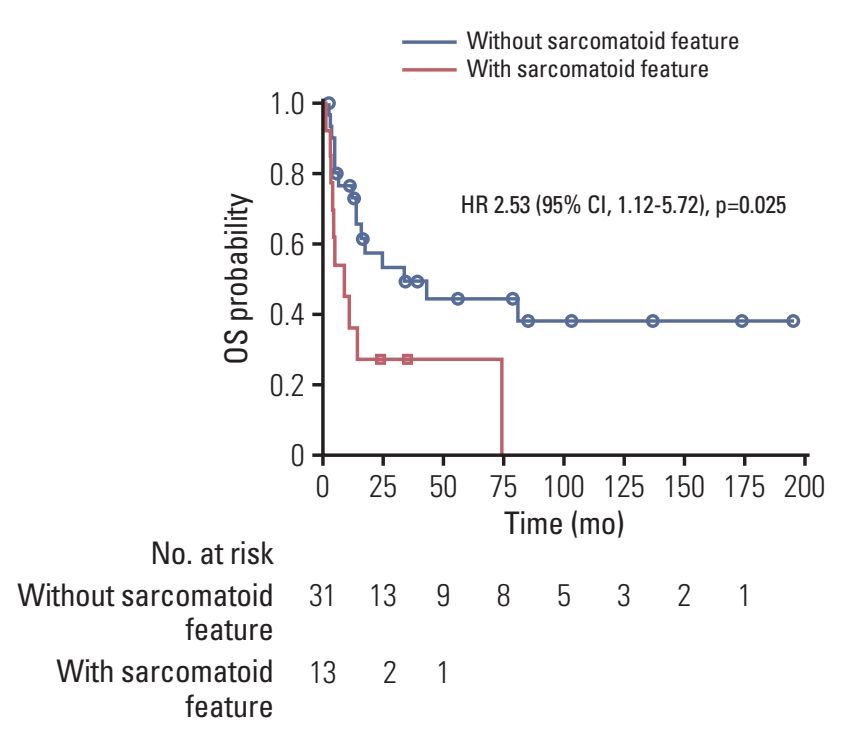

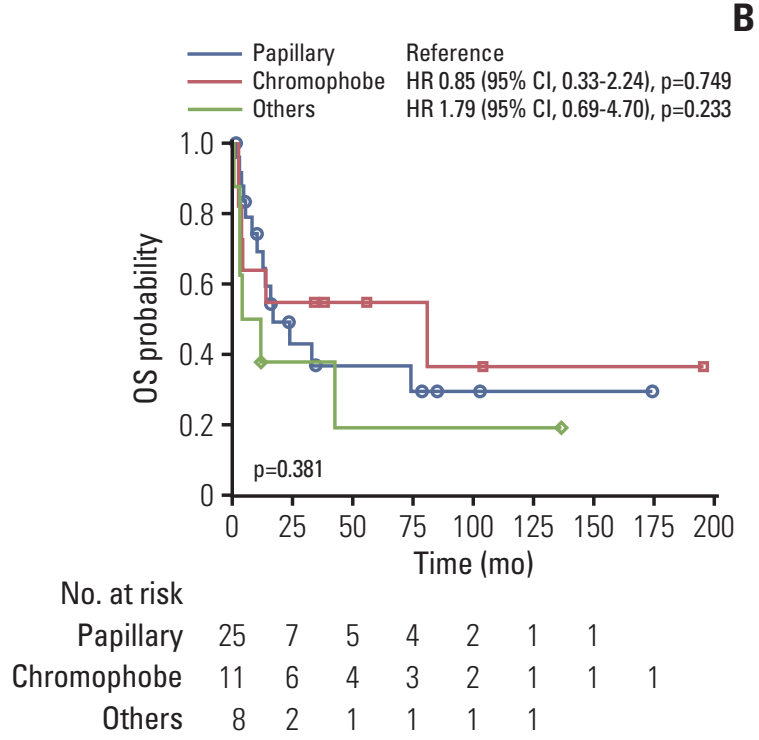

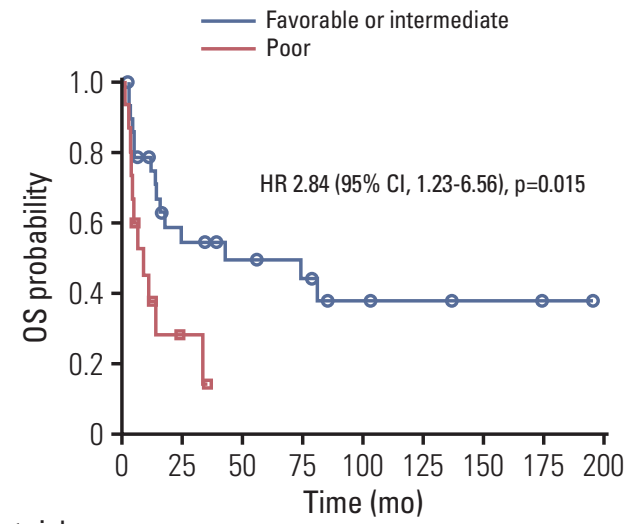

No. at risk

Favorable or $\begin{array}{lllllllll}29 & 13 & 10 & 8 & 5 & 3 & 2 & 1\end{array}$ intermediate

Poor $15 \quad 2$

Fig. 3. Kaplan-Meier curves of overall survival (OS) according to subgroups. (A) With or without sarcomatoid features. (B) Papillary, chromophobe, others. (C) Prognostic group by Advanced Renal Cell Cancer criteria. HR, hazard ratio; CI, confidence interval.

\section{Prognostic factors affecting survival}

In univariate analysis, factors such as previous nephrectomy $(\mathrm{p}<0.001)$ and favorable/intermediate prognosis defined by ARCC and MSKCC ( $\mathrm{p}=0.005$ and $\mathrm{p}=0.024$, respectively) were associated with improved PFS (Table 4). Factors that were associated with poor OS were poor ECOG performance status ( $\mathrm{p}=0.009)$, presence of sarcomatoid component $(\mathrm{p}=0.025)$, absence of previous nephrectomy $(\mathrm{p}<0.001)$, and poor prognosis defined by ARCC and MSKCC ( $\mathrm{p}=0.015$ and $\mathrm{p}=0.004$, respectively).

In multivariate Cox regression analysis, prognostic factor defined by ARCC was selected because it was the criteria used in the Global ARCC trial which showed that nccRCC with poor prognosis benefit from temsirolimus. MSKCC was disregarded in order to avoid interaction between the two parameters. Patients with prior nephrectomy tended to have better PFS (HR, 0.16; 95\% CI, 0.06 to 0.42; $\mathrm{p}<0.001$ ). Sarcomatoid component (HR, 3.07; 95\% CI, 1.12 to 8.39; $\mathrm{p}=0.029$ ) and previous nephrectomy (HR, 0.15 ; $95 \% \mathrm{CI}, 0.05$ to 0.45 ; 
Table 3. Summary of treatment-related adverse events

\begin{tabular}{|c|c|c|c|c|c|c|}
\hline & \multicolumn{6}{|c|}{ No. of patients (\%) } \\
\hline & All grades & Grade $\geq 3$ & All grades & Grade $\geq 3$ & All grades & Grade $\geq 3$ \\
\hline \multicolumn{7}{|c|}{ Symptoms and signs $(\mathrm{n}=30,68 \%)$} \\
\hline Anorexia & $5(15)$ & $2(6)$ & $3(30)$ & - & $8(18)$ & $2(5)$ \\
\hline Nausea/Vomiting & $2(6)$ & $1(3)$ & $1(10)$ & - & $3(7)$ & $1(2)$ \\
\hline Fatigue & $8(24)$ & $2(6)$ & $4(40)$ & $3(30)$ & $12(27)$ & $5(11)$ \\
\hline Stomatitis & $10(30)$ & $1(3)$ & $5(50)$ & $3(30)$ & $15(34)$ & $4(9)$ \\
\hline Hand-foot syndrome & $3(9)$ & - & - & - & $3(7)$ & - \\
\hline Rash & $5(15)$ & - & $2(20)$ & $1(10)$ & $7(16)$ & $1(2)$ \\
\hline Pruritus & $2(6)$ & - & $3(30)$ & - & $5(11)$ & - \\
\hline Headache & $1(3)$ & - & $1(10)$ & - & $2(5)$ & - \\
\hline Alopecia & $1(3)$ & - & - & - & $1(2)$ & - \\
\hline Edema & $1(3)$ & - & $2(20)$ & - & $3(7)$ & - \\
\hline Scrotal swelling & - & - & $1(10)$ & - & $1(2)$ & - \\
\hline Leg pain & - & - & $2(20)$ & - & $2(5)$ & - \\
\hline URI & $3(9)$ & - & $2(20)$ & - & $5(11)$ & - \\
\hline Diarrhea & - & - & $1(10)$ & - & $1(2)$ & - \\
\hline Insomnia & - & - & $1(10)$ & - & $1(2)$ & - \\
\hline \multicolumn{7}{|c|}{ Lab and imaging abnormalities $(n=27,61 \%)$} \\
\hline Anemia & $3(9)$ & - & - & - & $1(2)$ & - \\
\hline Leukopenia & $1(3)$ & - & $2(20)$ & $1(10)$ & $3(7)$ & - \\
\hline Thrombocytopenia & - & - & $1(10)$ & - & $1(2)$ & - \\
\hline Increased AST/ALT & $2(6)$ & - & $1(10)$ & - & $3(7)$ & - \\
\hline Increased creatinine level & $1(3)$ & - & $1(10)$ & - & $2(5)$ & - \\
\hline Hyperglycemia & $10(30)$ & $4(12)$ & - & - & $10(23)$ & $4(9)$ \\
\hline Hypercholesterolemia & $6(18)$ & - & $2(20)$ & - & $8(18)$ & - \\
\hline Hypertriglyceridemia & $5(15)$ & $4(12)$ & $2(20)$ & $1(10)$ & $7(16)$ & $5(11)$ \\
\hline Noninfectious pneumonitis & $7(21)$ & $1(3)$ & - & - & $7(16)$ & $1(2)$ \\
\hline
\end{tabular}

URI, upper respiratory tract infection; AST, aspartate aminotransferase; ALT, alanine aminotransferase.

$\mathrm{p}<0.001)$ were significantly associated with OS.

Notably, second-line treatment did not affect the OS. Only 11 patients $(25 \%)$ received second-line chemotherapy which included eight patients who received TKIs such as pazopanib, sunitinib, axitinib, and three patients who received chemotherapy (Table 1). Therefore, our results suggested that temsirolimus as first-line of treatment was crucial in determining the OS of nccRCC.

\section{Discussion}

This study included both prospective and retrospective data of temsirolimus as first-line treatment in treatmentnaïve Asian patients with metastatic/ recurrent nccRCC. All of the 34 patients from retrospective group were treated with the same standard protocol from the prospective study at
Yonsei Cancer Center. Since the majority of data was collected from a single center with consistent protocol, heterogeneity of data was minimized. Our results showed that patients had ORR of $11 \%$, DCR $83 \%$, mPFS of 7.6 months, and mOS of 17.6 months. When patients were further categorized by favorable/intermediate and poor prognosis group was defined by Hudes et al. [9] the mPFS and mOS for poor prognosis group were 4.7 and 9.2 months, respectively. These results are comparable to those of pivotal temsirolimus studies, particularly the Global ARCC trial.

Global ARCC trial, which was a randomized phase 3 study of temsirolimus versus interferon $\alpha$ or both for clear cell (586 patients) and nccRCC (40 patients), showed that patients defined as poor prognosis who were administered with temsirolimus had mPFS of 3.8 months and mOS of 10.9 months. Thus, temsirolimus has been used as standard treatment for nccRCC with poor prognosis. In our study, one-third of the patients were classified as poor-risk, which may explain why our study had longer mPFS and mOS. Therefore, temsiro- 


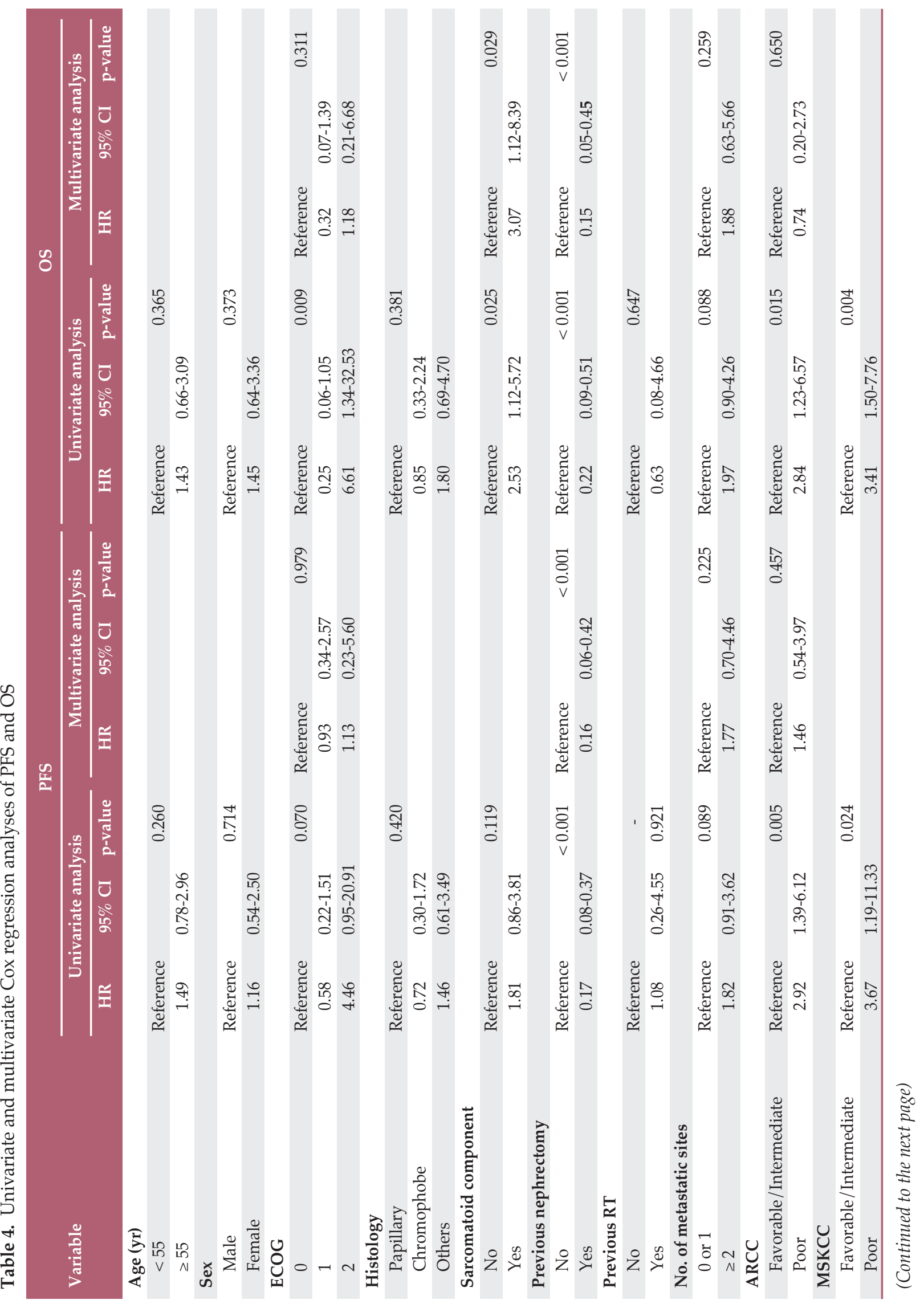




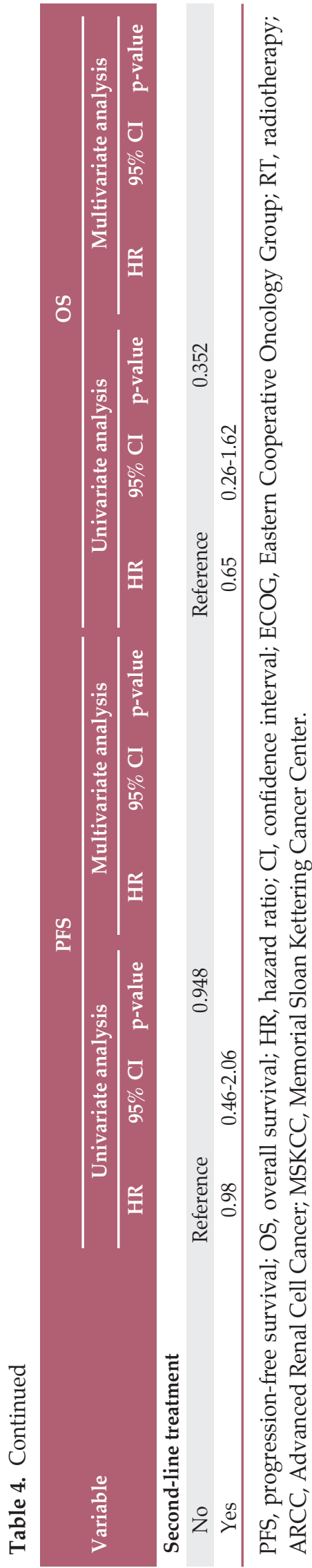

limus may not only benefit poor prognosis group, but also patients with less extensive metastatic nccRCC. It is important to note that there were more patients who were categorized as poor prognostic group by ARCC (15 patients, 34\%) than with MSKCC parameters (four patients, 9\%). Since MSKCC parameters have certain limitations in nccRCC, our study focused on the prognostic tool defined by Hudes et al. [9] in Global ARCC trial as reference data. IDMC model (International Metastatic Renal Cell Carcinoma) which was validated in ccRCC VEGFR TKI but not in nccRCC, was also not considered in this study.

Everolimus, an orally administered mTOR inhibitor in nccRCC, was also evaluated in ESPN (Everolimus versus Sunitinib Prospective Evaluation in Metastatic Non-clear Cell Renal Cell Carcinoma) [11] and ASPEN [12] studies. ESPN, a randomized phase 2 study compared the efficacy of everolimus and sunitinib in first-line setting in 73 subjects. Sunitinib, a vascular endothelial growth factor TKI, had better mPFS than that of everolimus (6.1 months vs. 4.1 months, $\mathrm{p}=0.25$ ) [11]. Similarly, everolimus versus sunitinib for patients with metastatic nccRCC (ASPEN), a randomized phase II study of 108 subjects, showed that sunitinib and everolimus had a median PFS of 8.3 months and 5.6 months, respectively [12].

Based on these results, everolimus cannot be recommended in first-line treatment for nccRCC. On the other hand, the efficacy of temsirolimus is comparable to that of sunitinib. Although temsirolimus has its limitation with weekly intravenous injection compared to relatively easy oral administration of sunitinib, temsirolimus has better manageable toxicity profiles compared to sunitinib. In our study, 84\% (37 patients) of subjects experienced AEs and 59\% (26 patients) had grade 3-related AEs, which were manageable with dose reductions and dose delays. Only four patients (9\%) discontinued treatment due to AEs.

In ASPEN study, 78\% (40 patients) receiving sunitinib experienced grade 3 or worse treatment-related AEs. Overall, $53 \%$ (27 patients) needed dose reductions and 14\% (7 patients) discontinued treatment due to treatment-related AEs. AEs related to sunitinib included hypertension, hand-foot syndrome, nausea/vomiting, diarrhea, and lab abnormalities such as hypothyroidism, thrombocytopenia, neutropenia, and elevated liver enzymes [12].

Pazopanib, a VEGFR TKI which was approved in advanced ccRCC, was also investigated in first-line setting in nccRCC. First-line pazopanib in nccRCC (PANORAMA) study which enrolled 37 patients, resulted in mPFS of 15.9 months and mOS of 17.3 months [16]. Pazobanib as secondline in 29 patients treated had an ORR of $28 \%$ with mPFS 16.5 months [17]. Pazobanib's role in nccRCC may need further validation. Table 5 summarizes ARCC, ESPN, ASPEN, and PANORAMA results. 
Table 5. Summary of first-line therapy for metastatic nccRCC

\begin{tabular}{lcccrc} 
Study & Our study & ARCC [9] & ESPN [11] & ASPEN [12] & PANORAMA [16] \\
$\begin{array}{l}\text { No. of nccRCCs } \\
\text { Treatment }\end{array}$ & $\begin{array}{l}\text { Temsirolimus } \\
\text { Prognosis }\end{array}$ & $\begin{array}{c}\text { Temsirolimus (40) } \\
\text { Any }\end{array}$ & $\begin{array}{c}73 \\
\text { Sunitinib (34) vs. } \\
\text { Everolimus (38) } \\
\text { Mostly favorable, } \\
\text { intermediate }\end{array}$ & $\begin{array}{c}\text { Sunitinib (51) vs. } \\
\text { Everolimus (57) }\end{array}$ & $\begin{array}{c}\text { Any } \\
\text { Pazopanib }\end{array}$ \\
ORR (\%) & 9 & 8.6 & 12 vs. 0 & 12 vs. 5.0 & 27 \\
PFS (mo) & 7.6 & 3.8 & 6.1 vs. 4.1 & 8.3 vs. 5.6 & 15.9 \\
OS (mo) & 17.6 & 10.9 & $\begin{array}{c}16.2 \text { vs. } 14.9 \\
\text { (p=0.18) }\end{array}$ & $\begin{array}{c}31.5 \text { vs. } 13.2 \\
\text { (p=0.60) }\end{array}$ & 17.3 \\
\hline
\end{tabular}

nccRCC, non-clear cell renal cell carcinoma; ARCC, Advanced Renal Cell Cancer; ESPN, Everolimus versus Sunitinib Prospective Evaluation in Metastatic Non-clear Cell Renal Cell Carcinoma; ASPEN, Everolimus versus Sunitinib for Patients with Metastatic Non-clear Cell Renal Cell Carcinoma; PANORAMA, first-line pazopanib in nccRCC; ORR, objective response rate; PFS, progression-free survival; OS, overall survival.

Although recent advancements have led to the development of new targeted drugs such as cabozantinib [18], a multi-targeted TKI and immune checkpoint inhibitors such as nivolumab in ccRCC, efficacy results on nccRCC are currently being investigated. The limitation of this study was the lack of data collected on parameters, such as lactate dehydrogenase, and a part of toxicity profiles in retrospective data. In addition, low incidence of nccRCC and reimbursement issues were obstacles in collecting larger sample size.

In conclusion, there seem to be several treatment options for nccRCC. Although temsirolimus and everolimus are both mTOR inhibitors, everolimus has failed to improve PFS and OS. Sunitinib and pazopanib are both VEGFR TKIs, but pazopanib as first-line nccRCC lacks data. Although 75\% (33 patients) did not receive second-line therapy due to fewer treatments options in South Korea, mOS was 17.6 months, indicating that the effect of temsirolimus directly translates to OS. In addition, temsirolimus not only benefits poor-risk group but also the favorable or intermediate-risk groups, and has comparable results to those of sunitinib.

Less extensive metastatic nccRCC may benefit from temsirolimus, regardless of histological variations and risk factors. Additional studies with larger sample size of nccRCC are needed to validate the results of this study.

\section{Conflicts of Interest}

Conflict of interest relevant to this article was not reported.
This research was partly supported by a grant from the National R\&D Program for Cancer Control, Ministry of Health and Welfare, Republic of Korea (1720150) and the National Cancer Center, Republic of Korea (NCC-1810861-1).

\section{Author Details}

${ }^{1}$ Division of Medical Oncology, Department of Internal Medicine, Yonsei Cancer Center, Yonsei University College of Medicine, Seoul, ${ }^{2}$ Song-Dang Institute for Cancer Research, Yonsei University College of Medicine, Seoul, ${ }^{3}$ Division of Medical Oncology, Department of Internal Medicine, St. Vincent's Hospital, College of Medicine, The Catholic University of Korea, Suwon, ${ }^{4}$ Department of Biostatistics, Yonsei University College of Medicine, Seoul, ${ }^{5}$ Department of Internal Medicine, Chungnam National University, Daejeon, ${ }^{6}$ Division of Hematology-Oncology, Department of Internal Medicine, Dongnam Institute of Radiological and Medical Sciences, Busan, 'Division of Hematology-Oncology, Pusan National University, Busan, ${ }^{8}$ Division of Hematology and Medical Oncology, Department of Internal Medicine, Seoul National University Bundang Hospital, Seongnam, ${ }^{9}$ Department of Preventive Medicine and Institute of Health Services Research, Yonsei University College of Medicine, Seoul, ${ }^{10}$ Division of Pathology, Yonsei University College of Medicine, Seoul, ${ }^{11}$ Brain Korea 21 Project for Medical Sciences, Yonsei University College of Medicine, Seoul, Korea

\section{Acknowledgments}

Prospective part of the study was endorsed by Korean Cancer Study Group (KCSG, www.kcsg.org) (GU11-03). 


\section{References}

1. Lopez-Beltran A, Kirkali Z, Montironi R, Blanca A, Algaba F, Scarpelli M, et al. Unclassified renal cell carcinoma: a report of 56 cases. BJU Int. 2012;110:786-93.

2. Moch H, Cubilla AL, Humphrey PA, Reuter VE, Ulbright TM. The 2016 WHO classification of tumours of the urinary system and male genital organs-part a: renal, penile, and testicular tumours. Eur Urol. 2016;70:93-105.

3. Tsimafeyeu I. Management of non-clear cell renal cell carcinoma: current approaches. Urol Oncol. 2017;35:5-13.

4. Zibelman M, Barth P, Handorf E, Smaldone MC, Kutikov A, Uzzo RG, et al. A review of interventional clinical trials in renal cell carcinoma: a status report from the ClinicalTrials.gov WebSite. Clin Genitourin Cancer. 2015;13:142-9.

5. Gore ME, Szczylik C, Porta C, Bracarda S, Bjarnason GA, Oudard $S$, et al. Final results from the large sunitinib global expanded-access trial in metastatic renal cell carcinoma. Br J Cancer. 2015;113:12-9.

6. Hong MH, Kim HS, Kim C, Ahn JR, Chon HJ, Shin SJ, et al. Treatment outcomes of sunitinib treatment in advanced renal cell carcinoma patients: a single cancer center experience in Korea. Cancer Res Treat. 2009;41:67-72.

7. Stadler WM, Figlin RA, McDermott DF, Dutcher JP, Knox JJ, Miller WH Jr, et al. Safety and efficacy results of the advanced renal cell carcinoma sorafenib expanded access program in North America. Cancer. 2010;116:1272-80.

8. Stadler WM, Figlin RA, Ernstoff MS, Curti B, Pendergrass K, Srinivas S, et al. The Advanced Renal Cell Carcinoma Sorafenib (ARCCS) expanded access trial: safety and efficacy in patients (pts) with non-clear cell (NCC) renal cell carcinoma (RCC). J Clin Oncol. 2007;25(18 Suppl):5036.

9. Hudes G, Carducci M, Tomczak P, Dutcher J, Figlin R, Kapoor A, et al. Temsirolimus, interferon alfa, or both for advanced renal-cell carcinoma. N Engl J Med. 2007;356:2271-81.

10. Dutcher JP, de Souza P, McDermott D, Figlin RA, Berkenblit A, Thiele A, et al. Effect of temsirolimus versus interferonalpha on outcome of patients with advanced renal cell carci- noma of different tumor histologies. Med Oncol. 2009;26:2029.

11. Tannir NM, Jonasch E, Albiges L, Altinmakas E, Ng CS, Matin $\mathrm{SF}$, et al. Everolimus versus sunitinib prospective evaluation in metastatic non-clear cell renal cell carcinoma (ESPN): a randomized multicenter phase 2 trial. Eur Urol. 2016;69:866-74.

12. Armstrong AJ, Broderick S, Eisen T, Stadler WM, Jones RJ, Garcia JA, et al. Final clinical results of a randomized phase II international trial of everolimus vs. sunitinib in patients with metastatic non-clear cell renal cell carcinoma (ASPEN). J Clin Oncol. 2015;33(15 Suppl):4507.

13. Hay N, Sonenberg N. Upstream and downstream of mTOR. Genes Dev. 2004;18:1926-45.

14. Del Bufalo D, Ciuffreda L, Trisciuoglio D, Desideri M, Cognetti F, Zupi G, et al. Antiangiogenic potential of the Mammalian target of rapamycin inhibitor temsirolimus. Cancer Res. 2006;66:5549-54.

15. Pantuck AJ, Zeng G, Belldegrun AS, Figlin RA. Pathobiology, prognosis, and targeted therapy for renal cell carcinoma: exploiting the hypoxia-induced pathway. Clin Cancer Res. 2003;9:4641-52.

16. Buti S, Bersanelli M, Maines F, Facchini G, Gelsomino F, Zustovich F, et al. First-Line Pazopanib in NOn-clear-cell Renal cArcinoMA: The Italian Retrospective Multicenter PANORAMA Study. Clin Genitourin Cancer. 2017;15:e609-14.

17. Jung KS, Lee SJ, Park SH, Lee JL, Lee SH, Lim JY, et al. Pazopanib for the treatment of non-clear cell renal cell carcinoma: a single-arm, open-label, multicenter, phase II study. Cancer Res Treat 2018;50:488-94.

18. Choueiri TK, Hessel C, Halabi S, Sanford B, Michaelson MD, $\mathrm{Hahn} \mathrm{O}$, et al. Cabozantinib versus sunitinib as initial therapy for metastatic renal cell carcinoma of intermediate or poor risk (Alliance A031203 CABOSUN randomised trial): progressionfree survival by independent review and overall survival update. Eur J Cancer. 2018;94:115-25. 